\title{
SHEAR BOND STRENGTH OF METALLIC BRACKETS: INFLUENCE OF SALIVA CONTAMINATION
}

\author{
Luciana Borges RETAMOSO ${ }^{1}$, Fabrício Mezzomo COLLARES ${ }^{1}$, Eduardo Silveira FERREIRA, Susana Maria Werner SAMUEL ${ }^{1}$
}

1- DDS, Graduate student, Pontifical Catholic University of Paraná, Curitiba, PR, Brazil.

2- DDS, MSc, PhD student, Dental Materials Laboratory, Dental School, Federal University of Rio Grande do Sul, Porto Alegre, RS, Brazil.

3- DDS, MSc, PhD, Professor of Orthodontics, Dental School, Federal University of Rio Grande do Sul, Porto Alegre, RS, Brazil.

4- DDS, MSc, PhD, Full Professor of Dental Materials, Dental Materials Laboratory, Dental School, Federal University of Rio Grande do Sul, Porto Alegre, RS, Brazil.

Corresponding address: Fabrício Mezzomo Collares - Ramiro Barcelos, 2492 - Laboratório de Materiais Dentários - Universidade Federal do Rio Grande do Sul - Porto Alegre, RS, Brasil - e-mail: fabriciodonto@gmail.com - Phone: 55 - 51 - 3308 - 5197

Received: May 26, 2008 - Modification: October 09, 2008 - Accepted: October 13, 2008

\begin{abstract}
$O$

bjective: To evaluate the influence of saliva contamination on shear bond strength and the bond failure pattern of 3 adhesive systems (Transbond XT, AdheSE and Xeno III) on orthodontic metallic brackets bonded to human enamel. Material and Methods: Seventy-two permanent human molars were cut longitudinally in a mesiodistal direction, producing seventy-two specimens randomly divided into six groups. Each system was tested under 2 different enamel conditions: no contamination and contaminated with saliva. In T, A and X groups, the adhesive systems were applied to the enamel surface in accordance with manufacturer's instructions. In TS, AS and XS groups, saliva was applied to enamel surface followed by adhesive system application. The samples were stored in distilled water at $37^{\circ} \mathrm{C}$ for $24 \mathrm{~h}$, and then tested for shear bond strength in a universal testing machine (Emic, DL 2000) running at a crosshead speed of $1 \mathrm{~mm} / \mathrm{min}$. After bond failure, the enamel surfaces were observed under an optical microscope at 40x magnification. Results: The control and contaminated groups showed no significant difference in shear bond strength for the same adhesive system. However, shear bond strength of T group (17.03 \pm 4.91$)$ was significantly higher than that of AS (8.58 \pm 1.73$)$ and XS $(10.39 \pm 4.06)$ groups $(\mathrm{p}<0.05)$. Regarding the bond failure pattern, TS group had significantly higher scores of no adhesive remaining on the tooth in the bonding area than other groups considering the adhesive remnant index (ARI) used to evaluate the amount of adhesive left on the enamel. Conclusion: Saliva contamination showed little influence on the 24-h shear bond strength of orthodontic brackets.
\end{abstract}

Key words: Adhesives. Orthodontic brackets. Saliva. Shear bond strength. Dental enamel.

\section{INTRODUCTION}

According to the well known efficacy of direct application of orthodontic brackets to tooth enamel, several studies ${ }^{5,10,22}$ have been performed in the search of materials that presents suitable resistance, friendly use, as well as durability in the course of treatment. Among the materials used for this purpose are the adhesive systems, due to their high bond strength to human enamel ${ }^{1}$ and low incidence of enamel fracture on bracket removal. The use of such material is only possible after the substrate acid etching and application of an adhesive coating to bond the composite resin or brackets to enamel.

When acid conditioner is presented in isolated bottles than primer and adhesives it constitutes the "etch-and-rinse" adhesive systems. The acid etching demineralizes the enamel prisms, creating a porous surface through which the adhesive can penetrate, resulting on a micro-mechanical retention.
The self-etching adhesive systems were developed to simplify the bonding procedure. Such systems simplify the steps of acid etching and primer in a single step, transforming it into a self-etching primer. The self-etching bond procedure leads to less technique sensitivity (i.e., no rinsing step) ${ }^{9,16,23}$ and fewer operative steps.

Contamination during the adhesion process reduces the longevity of the bonding materials, once it can alter the material properties ${ }^{6}$, substrate surface ${ }^{21}$ and cause problems in the bonding process ${ }^{19}$. In orthodontics, saliva contamination could lead to debonding of metallic brackets increasing treatment duration. The aim of this study was to verify the influence of saliva contamination on the bond strength and failure pattern of different adhesive systems used with a light-cured composite resin for bonding of metallic orthodontic brackets to human enamel. 


\section{MATERIAL AND METHODS}

This research protocol was first reviewed and approved by the local Research Ethics Committee.

The sample consisted of 72 extracted human healthy third molars which were randomly divided into four groups and stored in distilled water until the bonding procedure. The adhesive systems used and its components, composition and manufacturer are shown in Figure 1. Enamel surface of each specimen was polished with pumice at low speed, thoroughly washed with distilled water and dried. The bonding procedure for each group is shown in Figure 2.

Each adhesive system was tested under 2 different enamel conditions: with no contamination and contaminated with saliva. In T, A and X groups, the adhesive systems were applied to the enamel surface in accordance with manufacturer's instructions. In TS, AS and XS groups, saliva was applied to enamel surface immediately before the etching (TS) and acidic primer (AS and XS) steps. Tooth contamination was done with natural and stimulated human saliva from a male donor, who was instructed to brush his teeth and do not eat for $1 \mathrm{~h}$ before saliva collection. An amount of $3 \mu \mathrm{L}$ of saliva was applied to each tooth with a microbrush until the surface was totally contaminated for approximately $5( \pm 1) \mathrm{s}$. After saliva contamination, the enamel surface was not blown off and the adhesive systems were applied. In all groups, specimens were light-cured for $20 \mathrm{~s}$ with a light-curing unit (Curing Light XL 3000, 3M ESPE, St Paul, MN, USA) with light intensity of $550 \mathrm{~mW} /$ $\mathrm{cm}^{2}$, as measured with a radiometer (Model 100, Demetron,
Danbury, CT, USA).

The metallic brackets (Morelli ${ }^{\circledR}$, Sorocaba, SP, Brazil) were bonded on the central portion of the specimens surface with a light-cured resin (TransBond XT - 3M / Unitek Co., Minneapolis, MN, USA), according to the manufacturer's instructions, and cured at a distance of $5 \mathrm{~mm}$ for $40 \mathrm{~s}$. After bonding the brackets, the specimens were stored in distilled water at $37^{\circ} \mathrm{C}$ for $24 \mathrm{~h}$. Each specimen was measured with a digital caliper before de test. The mean bonded area was $14.28( \pm 0.5) \mathrm{mm}^{2}$.

The shear bond strength test was performed in a universal testing machine (EMIC DL2000, São José dos Pinhais, PR, Brazil) with a crosshead speed of $1 \mathrm{~mm} / \mathrm{min}$ with a guillotine device. After bracket debonding, the adhesive remnant index (ARI) was verified under an optical microscope at 40x magnification $^{21}$. The failure patterns were classified according to the following scores: $0=$ no adhesive remaining on the tooth in the bonding area; $1=$ less than half of the adhesive remaining; 2 = more than half of the adhesive remaining; and $3=$ all adhesive remaining, with a distinct impression of the bracket mesh.

In addition to descriptive statistical analysis (mean and standard deviation), the Kolmogorof-Smirnoff test was performed to verify the normality of the shear bond strength data. The analysis of the data was completed with ANOVA and multiple comparisons Tukey's test to determine whether difference existed among the groups. The ARI scores were analyzed by Kruskal-Wallis and Mann-Whitney tests. A significance level of 5\% was set for all analysis.

\begin{tabular}{|c|c|c|c|}
\hline ADHESIVE & COMPONENTS & COMPOSITION & MANUFACTURER \\
\hline \multirow[t]{2}{*}{$\begin{array}{c}\text { Transbond XT }(\mathrm{T}) \\
\text { (3-step etch and rinse) }\end{array}$} & Primer & $\begin{array}{l}\text { Primer: trietylenoglicol-dimethetil- } \\
\text { acrylate (45-55\%), Bis-GMA (45- } \\
55 \%)\end{array}$ & $\begin{array}{c}\text { 3M Unitek Dental Products, } \\
\text { Monrovia, CA, USA }\end{array}$ \\
\hline & Bond & $\begin{array}{l}\text { Adhesive: silane-treated quartz (70- } \\
\text { 80\%), BisGMA } \\
\text { (10-20\%), dichlorodimethylsinane } \\
\text { reaction product with silica ( } 2 \%)\end{array}$ & \\
\hline \multirow[t]{2}{*}{$\begin{array}{c}\text { AdheSE }(A) \\
\text { (2-step self-etching) }\end{array}$} & Primer & $\begin{array}{l}\text { Dimethacrylate, phosphonic } \\
\text { acid acrylate, water, stabilizers }\end{array}$ & $\begin{array}{l}\text { Ivoclar Vivadent, Schaan, } \\
\text { Principality of } \\
\text { Liechtenstein }\end{array}$ \\
\hline & Bond & $\begin{array}{l}\text { Dimethacrylate, HEMA, } \\
\text { silica, initiators and stabilizers }\end{array}$ & \\
\hline \multirow{2}{*}{$\begin{array}{l}\text { Xeno III }(X) \\
\text { (1-step self-etching; } \\
\text { two component } \\
\text { system) }\end{array}$} & Liquid A & $\begin{array}{l}\text { HEMA, purified water, ethanol, } \\
\text { 2,6-Di-tert-butyl-p hydroxy toluene, } \\
\text { nanofiller }\end{array}$ & $\begin{array}{l}\text { DeTrey Dentsply, } \\
\text { Konstanz, } \\
\text { Germany }\end{array}$ \\
\hline & Liquid B & $\begin{array}{c}\text { Pyro-EMA, PEM-F, UDMA, } \\
\text { BHT, Camphorquinone, EPD }\end{array}$ & \\
\hline
\end{tabular}

FIGURE 1- Components, formulations and manufacturers of the tested adhesive systems 


\begin{tabular}{|c|c|c|c|c|}
\hline \multicolumn{3}{|c|}{ Group* } & \multicolumn{2}{|c|}{ Bonding Procedure } \\
\hline $\mathrm{T}^{*}$ & Etching ${ }^{\star *}$ & Drying & - & $\begin{array}{l}\text { Primer application (15-20 s), placement of the resin paste on the } \\
\text { bracket, and light cured }\end{array}$ \\
\hline TS* & Etching** & Drying & Saliva & \\
\hline A & - & Drying & - & Primer application, left undisturbed for 30 s, air-dried. Bond \\
\hline AS & - & Drying & Saliva & $\begin{array}{l}\text { application, air-thin, light cured. Placement of the resin paste on } \\
\text { the bracket, and light cured }\end{array}$ \\
\hline$x$ & - & Drying & - & Liquids Aand B mixed, applied and left undisturbed (20 s), air thin, \\
\hline$x S$ & - & Drying & Saliva & $\begin{array}{l}\text { light cured. Placement of the resin paste on the bracket, and light } \\
\text { cured }\end{array}$ \\
\hline
\end{tabular}

FIGURE 2- Bonding procedure according to adhesive system used. * $\mathrm{T}=$ Transbond $\mathrm{XT}$; TS= Transbond with contamination; A= AdheSE; AS= AdheSE with contamination; $X=$ Xeno III; XS= Xeno III with contamination. ${ }^{* *} 15-\mathrm{s} 37 \%$ phosphoric acid etching and 15-s rinsing

TABLE 1- Shear bond strength means (in MPa) and standard deviation

\begin{tabular}{lc}
\hline Group (n) & Mean (standard deviation) \\
\hline $\mathrm{T}(12)$ & $17.03( \pm 4.91) \mathrm{a}$ \\
$\mathrm{TS}(12)$ & $12.80( \pm 8.27) \mathrm{a}, \mathrm{b}$ \\
$\mathrm{A}(12)$ & $13.53( \pm 2.37) \mathrm{a}, \mathrm{b}$ \\
$\mathrm{AS}(12)$ & $8.58( \pm 1.73) \mathrm{b}$ \\
X (12) & $11.92( \pm 3.04) \mathrm{a}, \mathrm{b}$ \\
XS (12) & $10.39( \pm 4.06) \mathrm{b}$ \\
\hline
\end{tabular}

Different letters indicate statistically significant difference $(p<0.05)$. $T=$ Transbond $X T ; T S=$ Transbond with contamination; $A=$ AdheSE; $A S=$ AdheSE with contamination; $\mathrm{X}=\mathrm{Xeno}$ III; $\mathrm{XS}=\mathrm{Xeno}$ III with contamination.

\section{RESULTS}

The mean values of shear bond strength are showed in Table 1. When compared the dry condition and saliva contamination for each material, no statistical significant difference were found. However, the group T ("etch and rinse" adhesive system), in dry condition, showed significantly higher bond strength than self-etching adhesive systems contaminated groups (AS, XS) $(\mathrm{p}<0.05)$.

The ARI scores were distributed as shown in Figure 3. The Kruskal-Wallis test showed statistically significant difference in the ARI scores $(\mathrm{p}<0.001)$. The Mann-Whitney pairwise test showed that contamination for the same adhesive system did not produce statistical significance. Statistically significant difference was observed between the self-etching and "etch and rinse" adhesive systems (Figure 3). TS group had significantly higher scores of no adhesive remaining on the tooth in the bonding area (score 0 ) then other groups.

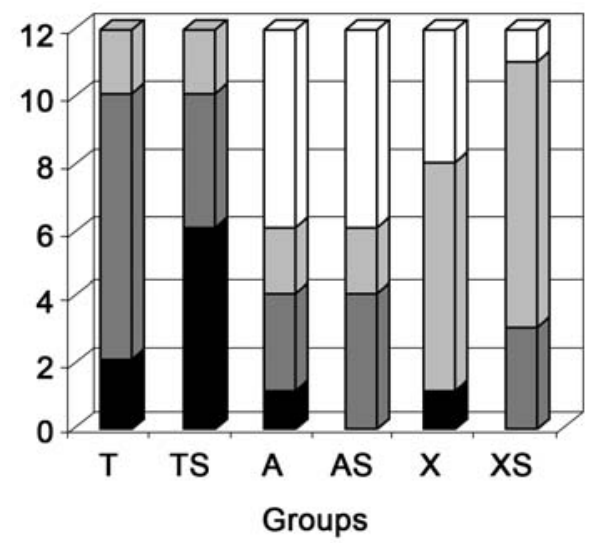

$\square$ Score 3

口Score 2

aScore 1

Score 0

FIGURE 3- Distribution of the adhesive remnant index scores. $\mathrm{T}=$ Transbond $\mathrm{XT}$; $\mathrm{TS}=$ Transbond with contamination; $A=$ AdheSE; $A S=$ AdheSE with contamination; $X=X$ Xeno III; $X S=$ Xeno III with contamination.

\section{DISCUSSION}

Direct bonding of orthodontic brackets using the acidetching of tooth substrate has become a common technique in orthodontics ${ }^{8,14}$. Acid etching creates a roughened enamel surface by dissolving calcium components. Enamel etching is a useful and accepted procedure for bonding orthodontic brackets. Moreover, there is a need for improving the capacity to obtain adequate bond strength, minimizing the amount of enamel loss ${ }^{9,17}$ and reducing the technique sensitivity of some adhesive systems. An effective adhesion to the enamel depends on the acidic capacity to demineralize the enamel prisms, producing porosities and allowing a low viscosity resin to penetrate into them, resulting in micromechanical retention. Acid etching technique in "etch and rinse" systems requires rinsing and drying before application of the adhesive resin. While the self-etching primers are 
able to produce simultaneously prisms demineralization and adhesive infiltration ${ }^{10,16}$ eliminating the clinical rinsing step.

Phosphoric acid etching has been blamed for decalcification and the development of white spot lesions around bonded orthodontic appliances ${ }^{4,20}$. Some reports have mentioned the mechanical damage to the enamel during debonding and removal of the remaining resin after acid etching ${ }^{11,12,15}$. Some studies observed by field-emission electron scanning microscopy (FE-SEM) more dissolution of the enamel surface as a result of phosphoric acid treatment than from self-etching primer procedures ${ }^{2,3}$. Thus, reduction of enamel loss may be achieved using self-etching primer adhesives.

Important issues should be pointed out during the choice of bonding materials for orthodontic brackets, such as their bond strength, longevity and ease of removal without damaging the dental structure. Those in vitro characteristics support the clinical practice through the shear bond strength and ARI scores. The correlation between in vitro and in vivo adhesive/resin interfaces and bond strength tests has been shown elsewhere ${ }^{24}$.

This "in vitro" research evaluated the influence of saliva contamination on the bond strength of different adhesive systems used with light-cured composite for bonding orthodontic brackets to human enamel. The results showed no significant difference in shear bond strength between contaminated and no contamination conditions for the same adhesive systems ${ }^{7,13}$. However, there are reports that demonstrate reduction of the bond strength when using selfetching primers ${ }^{3,12,17,22}$. Despite the difficult to compare absolute means results of different studies this partially agree with our findings that Transbond XT group (T) presented higher shear bond strength than the self-etching contaminated groups (AS and XS). The contamination was done after the acid etching step in group TS and before the self-etching primer application in groups AS and XS. Thus, saliva could buffer the acidic monomers reducing its capacity of etch the substrate decreasing the mean bond strength for this groups. Even though, there was no significant difference between the not contaminated and contaminated conditions in the self-etching adhesive system groups.

Restorative dentistry requires high bond strength and durability of adhesive procedures, while in Orthodontics the bracket adhesion to tooth substrate is temporary. When brackets debond, the failure at the bracket-adhesive interface or cohesively in adhesive is more desirable and safer than failure at the adhesive-enamel interface, since enamel fracture and crazing have been reported at the time of fracture ${ }^{13}$. The most frequent pattern of bonding failure in the self-etching groups occurred at the bracket-adhesive interface and none enamel fracture was observed. Moreover, saliva contamination did not influence the failure patterns of self-etching and the "etch and rinse" adhesive systems groups. Thus, it seems that self-etching primers does not represent a risk for irreversible damage to tooth substrate since few specimens presented remaining adhesive on enamel surface.

The present study used the same saliva application time for all groups (5 s). A prolonged contamination time reduces the bond strength for self-etching adhesive systems ${ }^{23}$ probably because of the monomers dissolution and the well known buffering capacity of saliva. Other important fact of saliva contamination is the biofilm formation on etched enamel surface ${ }^{18}$ that reduces the interpenetration capacity of etch-and-rinse systems monomers. Others studies are necessary to evaluate the influence of different times of contamination at brackets bond strength.

Considering the longevity of bonding procedure, there is evidence that bond strength decreases over time at the adhesive/tooth interface ${ }^{2}$. The self-etching adhesive systems need an aqueous medium to its components ionization. This ionization allows the acidic monomer to etch and simultaneously penetrate the surface ${ }^{16}$. However, these monomers are hydrophilic and so, more susceptible to hydrolytic degradation longitudinally ${ }^{6}$. In this study, saliva contamination showed influence at immediately shear bond strength of orthodontic brackets between "etch and rinse" and self-etch adhesive systems. Further studies are necessary to evaluate the longitudinal behavior of these adhesive systems on orthodontic brackets with or without saliva contamination as well as to support its application in the orthodontic treatment.

\section{CONCLUSIONS}

In conclusion, saliva contamination showed little influence on the immediate shear bond strength of orthodontic brackets.

\section{REFERENCES}

1- Artun J, Bergland S. Clinical trials with crystal growth conditioning as an alternative to acid-etch enamel pretreatment. Am J Orthod. $1984 ; 85(4): 333-40$

2- Bishara SE, Gordan VV, VonWald L, Jakobsen JR. Shear bond strength of composite, glass ionomer, and acidic primer adhesive systems. Am J Orthod Dentofacial Orthop. 1999;115(1):24-8.

3- Bishara SE, Oonsombat C, Ajlouni R, Denehy G. The effect of saliva contamination on shear bond strength of orthodontic brackets when using a self-etch primer. Angle Orthod. 2002;72(6):554-7.

4- Bishara SE, Ostby AW, Ajlouni R, Laffoon JF, Warren JJ. Early shear bond strength of a one-step self-adhesive on orthodontic brackets. Angle Orthod. 2006;76(4):689-93.

5- Bishara SE, VonWald L, Laffoon JF, Warren JJ. Effect of a self-etch primer/adhesive on the shear bond strength of orthodontic brackets. Am J Orthod Dentofacial Orthop. 2001;119(6):621-4.

6- Brown CR, Way DC. Enamel loss during orthodontic bonding and subsequent loss during removal of filled and unfilled adhesives. Am J Orthod. 1978;74(6):663-71.

7- Cacciafesta V, Sfondrini MF, De Angelis M, Scribante A, Klersy C. Effect of water and saliva contamination on shear bond strength of brackets bonded with conventional, hydrophilic, and self-etching primers. Am J Orthod Dentofacial Orthop. 2003;123(6):633-40. 
8- De Munck J, Van Landuyt K, Peumans M, Poitevin A, Lambrechts P, Braem $\mathrm{M}$, et al. A critical review of the durability of adhesion to tooth tissue: methods and results. J Dent Res. 2005;84(2):118-32.

9- De Munck J, Van Meerbeek B, Yoshida Y, Inoue S, Vargas M, Suzuki $\mathrm{K}$, et al. Four-year water degradation of total-etch adhesives bonded to dentin. J Dent Res. 2003;82(2):136-40.

10- El-Kalla IH, Garcia-Godoy F. Saliva contamination and bond strength of single-bottle adhesives to enamel and dentin. Am J Dent. 1997;10(2):837.

11- Ferracane JL. Hygroscopic and hydrolytic effects in dental polymer networks. Dent Mater. 2006;22(3):211-22.

12- Gorelick L, Geiger AM, Gwinnett AJ. Incidence of white spot formation after bonding and banding. Am J Orthod. 1982Feb;81(2):93-8.

13- Joseph VP, Rossouw E. The shear bond strengths of stainless steel and ceramic brackets used with chemically and light-activated composite resins. Am J Orthod Dentofacial Orthop. 1990;97(2):121-5.

14- Kawasaki M, Hayakawa T, Takizawa T, Sirirungrojying S, Saitoh K, Kasai K. Assessing the performance of a methyl methacrylate-based resin cement with self-etching primer for bonding orthodontic brackets. Angle Orthod. 2003;73(6):702-9.

15- Movahhed HZ, Ogaard B, Syverud M. An in vitro comparison of the shear bond strength of a resin-reinforced glass ionomer cement and a composite adhesive for bonding orthodontic brackets. Eur J Orthod. 2005;27(5):477-83

16- Ogaard B, Rolla G, Arends J. Orthodontic appliances and enamel demineralization. Part 1. Lesion development. Am J Orthod Dentofacial Orthop. 1988;94(1):68-73.

17- Python MM, Oliveira MV, Ruellas ACO, Bolognese AM, Romano FL. Shear bond strength of orthodontic brackets to enamel under different surface treatment conditions. J Appl Oral Sci. 2007;15(2):127-30.

18- Rego EB, Romano FL. Shear bond strength of metallic brackets photoactivated with light-emitting diode (LED) at different exposure times. J Appl Oral Sci. 2007;15(5):412-5.

19- Romano FL, Tavares SW, Nouer DF, Consani S, Magnani MBBA. Shear bond strength of metallic orthodontic brackets bonded to enamel prepared with Self-Etching Primer. Angle Orthod. 2005;75(5):849-53.

20- Saito K, Sirirungrojying S, Meguro D, Hayakawa T, Kasai K. Bonding durability of using self-etching primer with 4-META/ MMA-TBB resin cement to bond orthodontic brackets. Angle Orthod. 2005;75(2):260-5.

21- Silverstone LM, Hicks MJ, Featherstone MJ. Oral fluid contamination of etched enamel surfaces: an SEM study. J Am Dent Assoc. 1985;110(3):329-32.

22- Sirirungrojying S, Hayakawa T, Saito K, Meguro D, Nemoto K, Kasai $\mathrm{K}$. Bonding durability between orthodontic brackets and human enamel treated with megabond self-etching primer using 4-META/MMA-TBB resin cement. Dent Mater J. 2004;23(3):251-7.

23- Sirirungrojying S, Saito K, Hayakawa T, Kasai K. Efficacy of using self-etching primer with a 4-META/MMA-TBB resin cement in bonding orthodontic brackets to human enamel and effect of saliva contamination on shear bond strength. Angle Orthod. 2004;74(2):251-8.

24- Yamada R, Hayakawa T, Kasai K. Effect of using self-etching primer for bonding orthodontic brackets. Angle Orthod. 2002;72(6):558-64. 